\title{
Re: Laparoscopy-assisted percutaneous endoscopic gastrostomy using a "Funada-kit II"device by Takahashi T, Miyano G, Shiyanagi S, Lane GJ, Yamataka A [Pediatr Surg Int 2012 Sep 1 (Epub ahead of print)]
}

\author{
Philip C. H. Ng
}

Accepted: 15 October 2012/ Published online: 25 November 2012

(c) Springer-Verlag Berlin Heidelberg 2012

Dear Editor,

I am grateful for Messrs Takahashi et al. for highlighting in their original article above, the issues of proper fixation of the anterior gastric wall during gastrostomy. Their original technique incorporates a fundamental safeguard against the major flaw of the PEG technique which is the blind part of the procedure that transillumination does not address. We have thus come to describe and recommend our Laparoscopic approach [1]. This approach provides direct visual verification of the proper apposition of the gastric wall to the anterior abdominal wall while eliminating any possibility of inadvertent interposition of other structures such as the transverse colon [2]. It also provides an opportunity to fix the gastric wall under vision, requires neither special tools nor advanced expertise to perform safely [3, 4] and

can be easily taught and performed successfully under local anaesthetic.

\section{References}

1. Philip Ng CH (1994) Laparoscopic gastrostomy: a simple way to feed. Surg Laparosc Endosc 4(6):463-464

2. Hin PC (1996) Laparoscopic-assisted gastrostomy in 26 patients: indications and outcome at 2 years. J Laparoendosc Surg 6(1): $25-28$

3. Ng PC (1997) Single puncture laparoscopic-assisted gastrostomy. J Laparo Endosc Adv Surg Tech 7(3):173-175

4. Gossage JA, Cho A, Ng P CH Laparoscopic gastrostomy insertion, a safe and simple technique. Ann R Coll Surg Engl Vol 19 Issue 3: June 12, 2007 July; 89(5): 530 (Free PMC Article)
P. C. H. $\mathrm{Ng}(\bowtie)$

University Hospital Lewisham,

London, UK

e-mail: philipng85@hotmail.com 